\title{
Removal of $17 \alpha$-ethynylestradiol from aqueous solutions by a hybrid PAC/UF process
}

\author{
Qingsong $\mathrm{Li}^{1}{ }^{2 *}$, Xiaoyan $\mathrm{Ma}^{3}$, Naiyun $\mathrm{Gao}^{2}$ and Wenhai $\mathrm{Chu}^{2}$ \\ 'Water Resources and Environmental Institute, Xiamen University of Technology, Xiamen, Fujian, 361005, China \\ ${ }^{2}$ State Key Laboratory of Pollution Control and Resource Reuse, Tongji University, Shanghai 200092, China \\ ${ }^{3}$ College of Civil Engineering and Architecture, Zhejiang University of Technology, Hangzhou, Zhejiang 310014, China
}

\begin{abstract}
This study investigated the removal of 17a-ethynylestradiol (EE2) from water using activated carbon adsorption and powdered activated carbon/ultrafiltration (PAC/UF). EE2 was easily adsorbed by PAC. The adsorption of EE2 fitted the Freundlich model well. The influences of initial EE2 concentration, filtration rate, PAC dose, natural organic matter (NOM), and sodium dodecyl benzene sulfonate (SDBS) were investigated. The EE2 concentration and filtration rate had no significant effect on EE2 removal, whereas the addition of PAC had a significant effect on EE2 removal. The removal rate of EE2 increased dramatically from $7.01 \%$ to $80.03 \%$ as the PAC dose was increased from 0 to $10 \mathrm{mg} / \mathrm{L}$. Both SDBS and NOM decreased the EE2 removal efficiency. The removal efficiency of EE2 in the PAC/UF process decreased from $86.77 \%$ to $42.64 \%$ as the SDBS concentration was increased from 0 to $50 \mathrm{mg} / \mathrm{L}$. It was concluded that activated carbon adsorption and $\mathrm{PAC} / \mathrm{UF}$ can be used for the effective removal of EE2 from water.
\end{abstract}

Keywords: 17- $\alpha$-ethynylestradiol, adsorption, ultrafiltration, PAC/UF process, removal efficiency

\section{INTRODUCTION}

In recent years, the removal of steroidal oestrogens, which can cause endocrine disruption, has become an important topic in water treatment research (Ma et al., 2016; Grover et al., 2011). 17a-Ethynylestradiol (EE2), the most common oestrogenic compound found in water, is generally used as an oestradiol alternative for the treatment of menopausal symptoms. EE2 has been detected in surface water, groundwater, and drinking water (Alvarez et al., 2013; Nie et al., 2014; Pérez and Escandar, 2014). Even at low doses, EE2 in water can interfere with fetal sexual differentiation, cause genital cancer, and alter glucose metabolism (Aris et al., 2014; Karpova et al., 2007). For all these reasons, the European Union has recently added EE2 to a new'watch list; of emerging aquatic pollutants included in the Water Framework Directive (EC, 2013). Recently, environmental quality standards for EE2, promulgated as a part of the EU Water Framework Directive, have been set at $0.035 \mathrm{ng} / \mathrm{L}$ for EE2 (EC, 2015). Several methods for the removal of steroidal oestrogens from water have been explored. Conventional water treatment processes such as coagulation, flocculation, sedimentation, and filtration are not effective for removing EE2 (Johnson et al., 2005; Kuch and Ballschmitter, 2001; Schenck et al., 2012). Thus, the development of new methods for the efficient removal of this pollutant from water bodies is necessary.

Activated carbon, composed of amorphous carbon and varying amounts of ash, is commonly used as an adsorbent for the removal of micro-pollutants in the treatment of drinking water. It can effectively remove taste and odour $(\mathrm{T} \& \mathrm{O})$, colour, chlorinated organic compounds, pesticides, natural organic matter, and synthetic organic compounds (Asenjo et al., 2011; Cook et al., 2001; Drikas et al., 2009; Hnatukova et al.,

*To whom all correspondence should be addressed.

Tel. +86 5926291 097; fax: +86 5926291 522; e-mail: leetsingsong@sina.com Received: 31 January 2016; accepted in revised form: 5 January 2017
2011). Activated carbon adsorption has been cited by the US Environmental Protection Agency as one of the best available environmental control technologies.

Microfiltration (MF), ultrafiltration (UF), nanofiltration (NF), and reverse osmosis (RO) are promising membrane techniques used to remove water pollutants (Loo et al., 2012). However, only NF and RO can remove dissolved organic matter effectively. UF and MF are inefficient at removing dissolved organic matter, natural organic matter (NOM: e.g. lowmolecular-weight humic substances), and T\&O alone. Therefore, the removal of these compounds is achieved by combining other conventional techniques, such as adsorption on powdered activated carbon (PAC), or by membranes specially provided with adsorptive characteristics (e.g. affinity membranes, hollowfiber membrane adsorbers) (Urmenyi et al., 2005; Yuriy, 2006).

PAC was found to be an effective adsorbent for removing EE2. ( Yoon et al., 2003), but separating PAC efficiently from the treated effluent remains a technical challenge. In the PAC/ UF hybrid processes, membranes provide a physical barrier preventing the passage of PAC, thus ensuring rejection of the EE2 adsorbed on the PAC that otherwise would not be rejected by the membrane. The UF inlet pipeline and UF loop here serve as a reactor for mixing water and PAC, and for the adsorption of EE2. With PAC addition, low-pressure-driven and cost-effective UF may be employed to remove dissolved organic compounds.

Micro-pollutants and odour-causing compounds may be removed efficiently while maintaining good water quality by adjusting the PAC dosage during the process, thereby obtaining different feed water qualities. Several studies have already reported on the application of PAC/UF technology in water purification (Mozia and Tomaszewska, 2004; IvancevTumbas and Hobby, 2010; Song et al., 2009). However, only a few studies have applied this technology to the removal of steroidal oestrogens.

The aim of this study was to determine the efficiency of EE2 removal from water by activated carbon adsorption and the combined PAC/UF technology, with a particular focus 
on the influences of different operating factors, such as the initial concentration of PAC, membrane filtration rate, and the presence of sodium dodecyl benzene sulfonate (SDBS) and NOM. The EE2 removal mechanism during a combination of the $\mathrm{PAC/UF}$ and UF processes was also investigated. The results of this study provide a basis for the removal and control of steroidal oestrogens in water.

\section{METHODS}

\section{PAC/UF experiments}

A laboratory-scale apparatus (Fig. 1) was used for the PAC/ UF experiments. The UF module consisted of 185 hollow fibre membranes (cellulose tri-acetate, $100 \mathrm{kDa}$, aperture; $0.01 \mu \mathrm{m}$, inner diameter; $930 \mu \mathrm{m}$ : Aquasource, Degremont Technologies, Toulouse, France) with an effective filtration area of $0.11 \mathrm{~m} 2$.

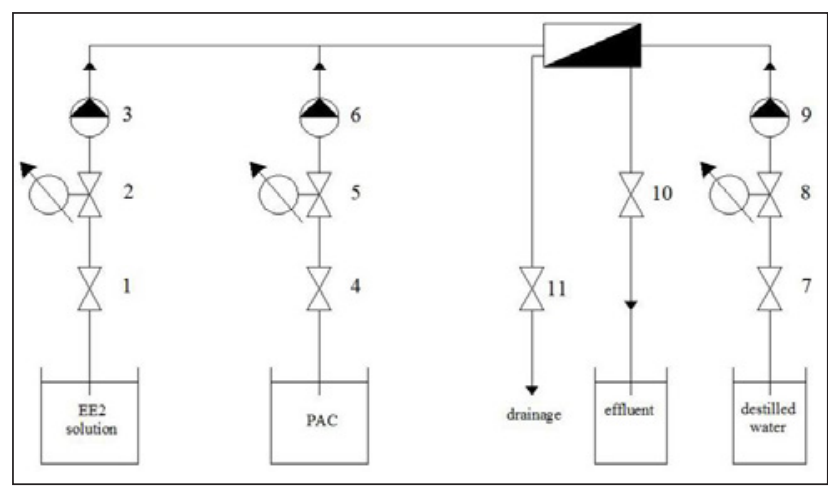

Figure 1

Schematic diagram of the PAC/UF system: (1) valve, (2) pressure gauge, (3) pump, (4) valve, (5) pressure gauge, (6) pump, (7) valve, (8) pressure gauge, (9) pump, (10) valve, (11) valve

For the PAC/UF process, a solution of PAC1\# (a commercially available PAC used in the experiments) was prepared and mixed with the source water by continuously adding it to the pipe using a diaphragm pump.

The dead-end filtration mode was adopted. PAC/UF experiments were conducted at a pressure of $0.3 \mathrm{MPa}$ and a filtration time of $30 \mathrm{~min}$, with backwashing conducted every 30 $\mathrm{min}$. For each filtration period, the average residence time of PAC was 15 min.

Under the assumption that the initial flux should be recovered, the backwashing duration was determined to be $120 \mathrm{~s}$ during the first backwashing procedure. Distilled water was used as the cleaning medium. At each designated sampling time, a 30 $\mathrm{mL}$ aliquot was collected for analysis.

In this study, the effect of several key operating parameters (i.e. initial EE2 concentration, membrane filtration rate (6-22 L min), PAC type, and dosage of PAC (0-10 mg/L), NOM $(0-0.1558 \mathrm{~cm}-1)$, and SDBS $(0-50 \mathrm{mg} / \mathrm{L}))$ on EE2 removal was assessed. For UF treatment alone, the filtration rate was $15 \mathrm{~L} / \mathrm{min}$, except for the experiment investigating the effect of filtration rate. For the PAC/UF process, the filtration rate was $15 \mathrm{~L} / \mathrm{min}$, and dosage of PAC was $10 \mathrm{mg} / \mathrm{L}$, except for the experiment investigating the effect of PAC dosage. Considering the analytical limit and UF (or PAC/UF process) removal efficiency, EE2 concentrations were higher than those generally found in drinking water. In our experiment, EE2 concentration was set as $70 \mu \mathrm{g} / \mathrm{L}$ (UF) and $250 \mu \mathrm{g} / \mathrm{L}$ (PAC/UF process), respectively.
The procedure and conditions were the same as described above. During the PAC/UF process, each experiment was undertaken in triplicate.

\section{Activated carbon performance}

Three commercial powdered activated carbons (PAC1\#, PAC2\#, and PAC3\#) were purchased from Huaqing Activated Carbon Group Co., Ltd., (Shanxi,China). Table 1 gives the characteristics of the powdered activated carbons that were applied. We targeted EE2 $(0-1000 \mu \mathrm{g} / \mathrm{L})$ as the material to be removed in the adsorption studies.

Prior to use, the activated carbon was soaked with deionized water, fast shocked, and then baked for $3 \mathrm{~h}$ at $105^{\circ} \mathrm{C}$. The resulting PACs were made into a suspension with deionized water, to a final concentration of $5 \mathrm{~g} / \mathrm{L}$. The carbon paste was diluted into different concentrations in $500 \mathrm{~mL}$ conical flasks. The rate of oscillation was 160 times/min for $24 \mathrm{~h}$.

\section{Reagents and sample preparation}

EE2 (chromatographically pure) and acetonitrile (HPLC grade) were obtained from Sigma (Sigma-Aldrich Corporation, St. Louis, MO, USA). All other chemicals were of analytical grade and used as received. The simulated EE2-contaminated water was prepared as follows. A quantity of EE2 was dissolved in $5 \mathrm{~mL}$ acetonitrile. Subsequently, the solution was diluted with distilled or tap water to the desired EE2 concentration. The quality indices of the experimental water are given in Table 2.

\section{Analytical method}

High-performance liquid chromatography (LC-2010AHT: Shimadzu, Kyoto, Japan) was used to determine the concentration of the adsorbed EE2. The working conditions were as follows: column of shim-pack VP-ODS $(150 \times 4.6 \mathrm{~mm}$ i.d. $)$, mobile phase of acetonitrile and water (50:50), flow rate of 0.8 $\mathrm{mL} / \mathrm{min}$, detection wavelength of $200 \mathrm{~nm}$, and the column was maintained at $40^{\circ} \mathrm{C}$.

The standard deviation, relative standard deviation, method detection limit,and reliable quantitation limit of EE2 were $0.20 \%$, $2.07 \%, 0.63 \mu \mathrm{g} / \mathrm{L}$, and $2.1 \mu \mathrm{g} / \mathrm{L}$, respectively.

The removal efficiency of EE2 was determined using the following equations:

Removal $(\%)=\left(1-\left(C^{\text {effluent }} / C^{\text {inlet }}\right)\right) \times 100$

where: $\quad C_{\text {inlet }}$ and $C_{\text {effluent }}$ indicate the inlet and effluent concentrations, respectively.

\section{RESULTS AND DISCUSSION}

\section{Adsorption of EE2 on selected active carbon}

PAC adsorption can be quantitatively analysed by a mathematical approach. The Freundlich equation is frequently used to describe the adsorption capacity of pharmaceutically active compounds (PHACs) and endocrine disrupting chemicals (EDCs) (Delgado et al., 2012). The bottle-point technique was used to derive the adsorption isotherm for EE2 at room temperature and the same $\mathrm{pH}$ conditions.

The equilibrium concentration and adsorption of EE2 was determined using the Freundlich model to fit the experimental 
TABLE 1

Characteristics of powdered activated carbon (PAC) used in the experiments

\begin{tabular}{|c|c|c|c|c|c|}
\hline No. & Type & Ash content (wt\%) & lodine adsorption (mg/g) & Loss on drying (\%) & Sieve mesh \\
\hline PAC1\# & WPH-C DG0103-01 & 14.24 & 846 & 6.24 & $\begin{array}{c}99 \%<200 \text { mesh } \\
97 \%<325 \text { mesh }\end{array}$ \\
\hline PAC2\# & BG-HHM HYS0106-8 & $5.1-6$ & $700-877.37$ & $9.5-10$ & $\begin{array}{c}95 \%<200 \text { mesh } \\
71 \%<325 \text { mesh }\end{array}$ \\
\hline PAC3\# & BG-HHM HYS0106-9 & $4.32-6$ & $700-890$ & $8.5-10$ & $\begin{array}{c}91 \%<200 \text { mesh } \\
68 \%<325 \text { mesh }\end{array}$ \\
\hline
\end{tabular}

\begin{tabular}{|c|c|c|c|c|c|}
\hline \multicolumn{6}{|c|}{$\begin{array}{c}\text { TABLE } 2 \\
\text { Water quality indices of experimental water }\end{array}$} \\
\hline & $\mathrm{pH}$ & $\begin{array}{l}\mathrm{TOC} \\
(\mathrm{mg} / \mathrm{L})\end{array}$ & $\begin{array}{l}\text { Turbidity } \\
\text { (NTU) }\end{array}$ & Conductivity ( $\mu \mathrm{s} / \mathrm{cm})$ & $\mathbf{U V}_{254}(\mathbf{c m}-\mathbf{1})$ \\
\hline Distilled water & $7.13 \sim 7.56$ & $1.370 \sim 1.670$ & 0 & $<20$ & $<0.006$ \\
\hline Tap water & $6.95 \sim 7.43$ & $4.601 \sim 7.023$ & $0.15 \sim 0.45$ & $606 \sim 720$ & $0.090 \sim 0.123$ \\
\hline
\end{tabular}

TABLE 3

Fitting parameters of the Freundlich adsorption isotherm model

\begin{tabular}{|c|c|c|c|}
\hline Type & Freundlich Equation & Parameter & $\boldsymbol{R}^{\mathbf{2}}$ \\
\hline PAC 1\# & $q_{\mathrm{e}}=1.2463 C_{\mathrm{e}}^{0.6273}$ & $K_{\mathrm{f}}=1.2463 ; 1 / \mathrm{n}=0.6273$ & 0.9050 \\
\hline PAC 2\# & $q_{\mathrm{e}}=0.8274 C_{\mathrm{e}}^{0.6008}$ & $K_{\mathrm{f}}=0.8274 ; 1 / \mathrm{n}=0.6008$ & 0.8558 \\
\hline PAC 3\# & $q_{\mathrm{e}}=8.8272 C_{\mathrm{e}}^{0.3184}$ & $K_{\mathrm{f}}=8.88272 ; 1 / \mathrm{n}=0.3184$ & 0.8986 \\
\hline
\end{tabular}

data for the adsorption of EE2 on PAC. The adsorption isotherm parameters of the fitting equation for the adsorption tests and the correlation coefficients are listed in Table 3.

Table 3 shows that the Freundlich adsorption isotherm model fitted the experimental data well, with PAC producing correlation coefficients of 0.8986 to 0.9050 . Therefore, the Freundlich isotherm model was considered to represent the EE2 adsorption process of PAC well.

The $K_{\mathrm{f}}$ values in the Freundlich model describe the adsorption capacity of activated carbon. The larger the $K_{\mathrm{f}}$ value, the greater the adsorption capacity per unit weight of carbon.

The Freundlich constant, $1 / n$, reflects the affinity of the activated carbon and contaminants.

The $K_{\mathrm{f}}$ values for PAC3\# (coconut shell carbon) and PAC1\# were all greater than 1 (8.88272 and 1.2463 , respectively), while the $K_{\mathrm{f}}$ value for PCA2\# was 0.8274 (i.e. less than 1). These results indicated that PAC3\# had the greatest adsorption capacity. The $1 / n$ values of the Freundlich model varied only slightly, with values between 0.3184 and 0.6273 , indicating that EE2 was readily adsorbed by the activated carbon.

Several studies have shown varying EDC/PHAC removal efficiencies using activated carbon in a variety of drinking water sources. The parameters of the Freundlich adsorption isotherm model for EE2 $\left(K_{\mathrm{f}}: 1.25-2.08,1 / n\right.$ : 0.327-1.760) were observed by Joseph et al. (2013). PAC was found to be an effective adsorbent for removing BPA and EE2; degrees of removal were in the range of $34-99 \%$. The varying EDC/PHAC removal efficiencies using activated carbon depend on the type of PAC and the presence of natural organic matter in the source water, surface area, pore structure, and thermostability (Yoon et al., 2003) .

\section{PAC/UF treatment}

\section{Effect of initial EE2 concentration on UF treatment alone}

The effect of the different EE2 initial concentrations on UF treatment alone is shown in Fig. 2.

As shown in Fig. 2, the UF process alone achieved an EE2 removal of 5.93-6.03\%, and no obvious difference in EE2 removal between experiments was observed. This result indicates that the removal of EE2 by UF is negligible.

Yoon et al. (2007) studied the removal of EDCs (including E1, E2, E3, and EE2), and pharmaceuticals and personal care products (PPCPs) from water using UF membranes and showed

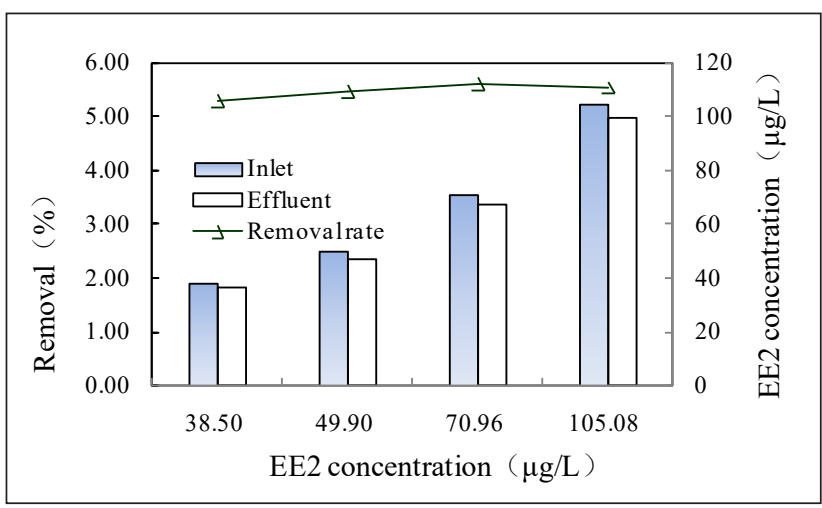

Figure 2

Effect of the initial concentration of EE2 on its removal efficiency by UF treatment alone (conditions: filtration rate $=15 \mathrm{~L} / \mathrm{min}$ ) 
that the UF membrane retained hydrophobic EDC/PPCPs due mainly to hydrophobic adsorption. This study has confirmed that UF was not efficient at removing EE2. In addition, the initial concentration of EE2 did not significantly affect its removal during direct filtration because the UF membrane MWCO was relatively large and cannot reject EE2 effectively. The 5-6\% EE2 removal rate was mainly attributed to the initial adsorption on the UF membrane.

\section{The effect of membrane filtration rate on EE2 removal}

The effect of different filtration rates on on UF treatment alone is shown in Fig. 3.

At filtration rates of $6,10,12$, and $15 \mathrm{~L} / \mathrm{min}$, the removal rates of EE2 were 5.94\%, 5.63\%, 5.61\%, and 6.04\%, respectively. The EE2 removal efficiencies were not significantly different from each other, indicating that the membrane filtration rate did not have a significant effect on EE2 removal.

\section{Effect of the addition of PAC on EE2 removal}

The removal of EE2 using UF alone was poor. Preliminary experiments indicated that PAC had a satisfactory adsorption performance and that the UF membrane can retain PAC, thus producing a solid-liquid separation system. Therefore, the PAC and UF membrane processes may be combined to remove EE2 more effectively from water.

Figure 4 shows the effect of PAC dosage on EE2 removal by a combined UF and PAC process.

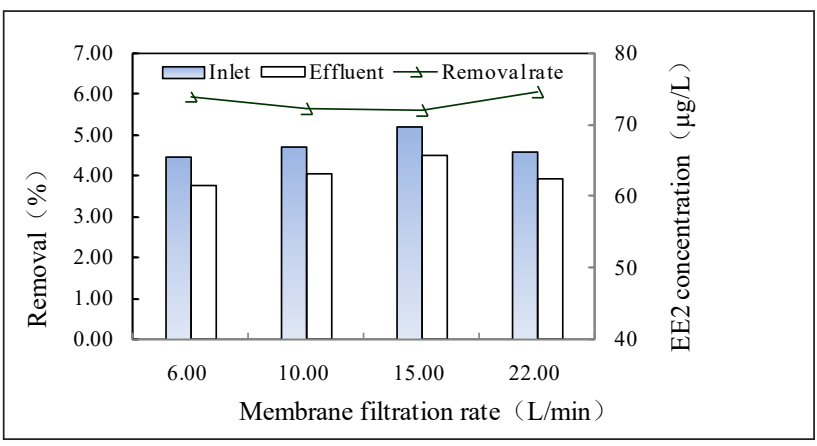

Figure 3

Effect of membrane filtration rate on the removal efficiency of EE2 (conditions: $[E E 2]_{0}=70 \mu \mathrm{g} / \mathrm{L}$ )

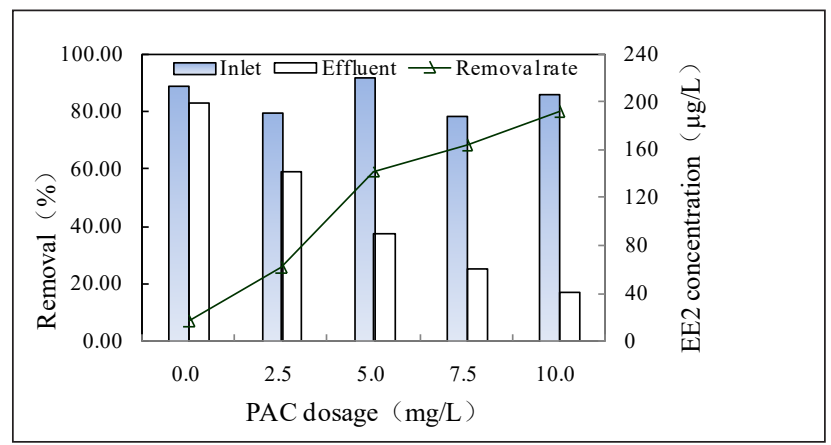

Figure 4

Effect of PAC dosage on the removal efficiency of EE2 (conditions: $[E E 2]_{0}=250 \mu \mathrm{g} / \mathrm{L}$, filtration rate $=15 \mathrm{~L} / \mathrm{min}$ )
EE2 removal efficiency increased from about 7.01\% without PAC to around $25.53 \%$ when $2.5 \mathrm{mg} / \mathrm{L}$ of PAC was used, and increased again to $59.21 \%, 68.15 \%$, and $80.03 \%$ when $5.0,7.5$, and $10 \mathrm{mg} / \mathrm{L}$, respectively, of PAC was added. It was found that the combination of UF and adsorption on PAC was more effective for EE2 removal than UF alone. PAC addition enhanced EE2 removal at the concentrations tested. This result was to be expected as an increase in the PAC dose applied would lead to more sites being available to adsorb EE2. The EE2 removal was mainly attributed to $\mathrm{PAC}$ adsorption during the PAC/UF process.

EE2 removal efficiency increased significantly with increasing PAC dosage. The fit of the regression line between EE2 removal and PAC dosage is shown in Fig. 5. It can be seen from the figure that EE2 removal was positively correlated with PAC dosage. These results are similar to the results obtained by Lee et al. (Lee et al., 2009); i.e., EE2 removal efficiency increased with increasing PAC dosage. The removal efficiency can be controlled by varying the $\mathrm{PAC}$ dosage according to the $\mathrm{EE} 2$ concentration, so that the desired quality of the treated water can be maintained.

\section{Effect of NOM on EE2 removal}

Natural water is a complex matrix that contains large amounts of NOM, such as polysaccharides, proteins, and humic substances. The presence of these compounds is likely to have an effect on EE2 removal. An amount of humic acid (10 mg/L) was added to distilled water to simulate NOM. $U V_{254}$ was used as an indicator of the NOM content of water.

The effect of NOM on EE2 removal was determined by varying the NOM concentration (Fig. 6).

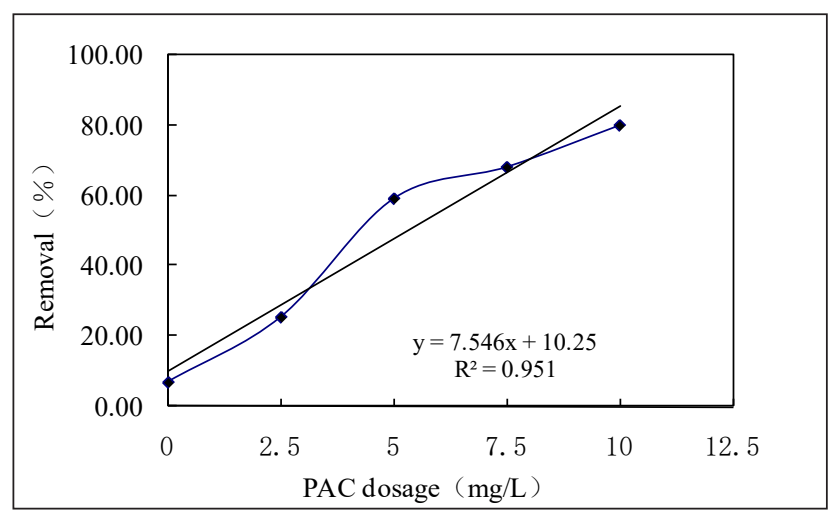

Figure 5

Effect of PAC dosage on the removal efficiency of EE2

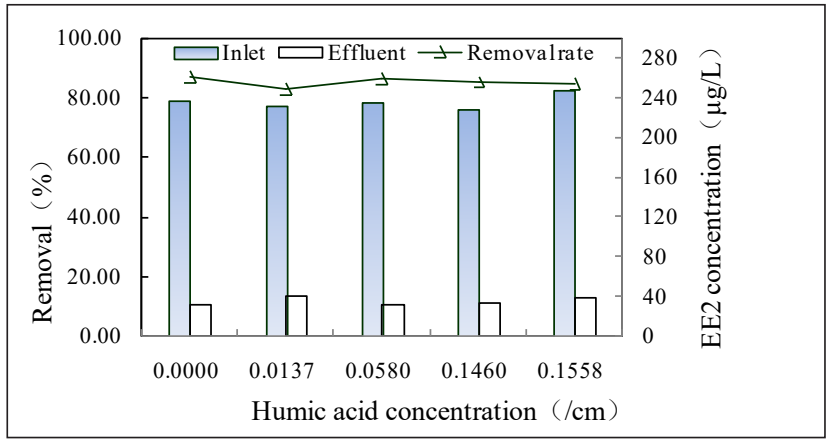

Figure 6

Effect of NOM on the removal efficiency of EE2 (conditions: $[E E 2]_{0}=250$ $\mu \mathrm{g} / \mathrm{L},[P A C]_{0}=10 \mathrm{mg} / \mathrm{L}$, filtration rate $=15 \mathrm{~L} / \mathrm{min}$ ) 
When the absorption values at $254 \mathrm{~nm}$ were $0,0.0137,0.058$, 0.14 , and $0.1558 \mathrm{~cm}^{-1}$, the EE2 removal rates achieved using the combined PAC/UF process were $86.77,82.81,86.17,85.5$, and $84.42 \%$, respectively.

The presence of NOM can decrease the EE2 removal efficiency, although the decrease can be negligible. NOM exhibits good physiological activity, adsorption functionality, and complexation ability. It can adsorb soluble organic matter and heavy metal ion contaminants in water (Hutaf et al., 2004). However, NOM can enter PAC apertures. It can block the pore channels of the activated carbon, thereby hindering the removal of contaminants by adsorption. EE2 adsorption on the activated carbon decreased significantly when the NOM concentration increased in our earlier experiment, but no significant decrease in EE2 removal was observed in the combined PAC/UF process. This may be attributed to the possible adsorption of EE2 by the NOM retained on the UF surface. The positive effect of NOM in accelerating the adsorption process was greater than its negative blocking effect. Therefore, the addition of NOM had only a slight effect on EE2 removal.

\section{Effect of SDBS on EE2 removal}

SDBS is an important environmental pollutant found in surface water. In this study, SDBS was selected as a typical representative contaminant, and its influence on the PAC/UF was determined at different concentrations (Fig. 7).

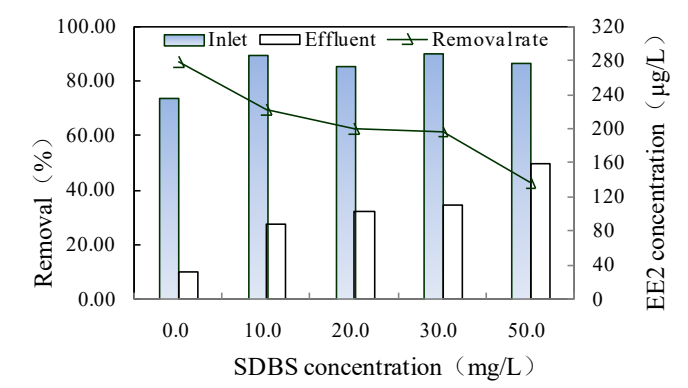

Figure 7

Effect of anionic synthetic detergent on the removal efficiency of EE2 (conditions: $[E E 2]_{0}=250 \mu \mathrm{g} / \mathrm{L},[P A C]_{0}=10 \mathrm{mg} / \mathrm{L}$, filtration rate $=15 \mathrm{~L} / \mathrm{min}$ )

The EE2 removal rates in the combined PAC/UF process decreased from $86.77 \%$ to $42.64 \%$ as the concentration of SDBS increased from 0 to $50 \mathrm{mg} / \mathrm{L}$. Therefore, the removal efficiency of EE2 was greatly reduced with an increase in the SDBS concentration in the combined PAC/UF process.

SDBS can be easily and rapidly adsorbed by PAC. It was found that the removal efficiency of SDBS reached $42.4 \%$ after 5 min of contact (Rivera-Utrilla et al., 2006), which indicated that SDBS did compete with EE2 for adsorption sites. The reduction in the EE2 removal rate may be due to adsorption sites being mainly occupied by SDBS, thereby reducing the adsorption capacity of PAC for EE2.

\section{CONCLUSION}

The removal of EE2 by adsorption and a PAC/UF hybrid process was investigated. The results indicated that EE2 was readily removed by PAC and a combined PAC/UF process. A removal efficiency of greater than $80 \%$ was achieved by the PAC/ UF process for a PAC dosage of $10 \mathrm{mg} / \mathrm{L}$. In the UF process, conducted without the addition of PAC, only $5 \%$ of EE2 was eliminated.

The removal efficiency of EE2 was found to be affected by the PAC dosage, and the SDBS and NOM content. SDBS and NOM decreased EE2 removal in the hybrid process. The presence of other compounds besides SDBS can also significantly reduce EE2 removal efficiency; therefore, the impact of the presence of other relevant micropollutants should be further addressed. Because $\mathrm{PAC/UF}$ does not generate intermediate breakdown products that exhibit oestrogenic activity, it is a promising technology for removing oestrogens from water. Further work is required to explore the effect of PAC additions on flux and permeate quality, and to determine the cleaning strategy for the PAC/UF process.

\section{ACKNOWLEDGMENTS}

This study was supported in part by the National Natural Science Foundation of China (Grant No. 51378446, 51408518); the Natural Science Foundation of Fujian Province of China (No. 2017Y01010018, 2016J01695), New Century Excellent Talents in Fujian Province University (JA14227), the Science and Technology Bureau of Xiamen (3502Z20131157,3502Z20150051), Provincial Training Program of Innovation and Entrepreneurship for Undergraduates (201611062182).

\section{REFERENCES}

ALVAREZ DA, SHAPPELL NW, BILLEY LO, BERMUDEZ DS, WILSON VS, KOLPIN DW, PERKINS SD, EVANS N, FOREMAN WT, GRAY JL and co-authors (2013) Bioassay of estrogenicity and chemical analyses of estrogens in streams across the United States associated with livestock operations. Water Res. 47 (10) 3347-3363. https://doi.org/10.1016/j.watres.2013.03.028

ARIS AZ, SHAMSUDDIN A S and PRAVEENA SM (2014) Occurrence of $17 \alpha$-ethynylestradiol (EE2) in the environment and effect on exposed biota: a review. Environ. Int. 69 104-119. https://doi. org/10.1016/j.envint.2014.04.011

ASENJO NG, ÁLVAREZ P, GRANDA M, BLANCO C, SANTAMARíA $\mathrm{R}$ and MENÉNDEZ R (2011) High performance activated carbon for benzene/toluene adsorption from industrial wastewater. J. Hazardous Mater. 192 1525-1532. https://doi.org/10.1016/j.jhazmat.2011.06.072

BAKER H and KHALILI F (2004) Analysis of the removal of lead (II) from aqueous solutions by adsorption onto insolubilized humic acid: temperature and $\mathrm{pH}$ dependence. Anal. Chim. Acta 516 (1 2) 179-186. https://doi.org/10.1016/j.aca.2004.03.068

COOK D, NEWCOMBE G and SZTAJNBOK P (2001) The application of powdered activated carbon for MIB and Gesmin removal: predicting PAC doses in four raw waters. Water Res. 35 1325-1333. https://doi. org/10.1016/S0043-1354(00)00363-8

DELGADO LF, CHARLES P, GLUCINA K and MORLAY C (2012) The removal of endocrine disrupting compounds, pharmaceutically activated compounds and cyanobacterial toxins during drinking water preparation using activated carbon - A review. Sci. Total Env. 435-436 509-525. https://doi.org/10.1016/j.scitotenv.2012.07.046

DRIKAS M, DIXON M and MORRAN J (2009) Removal of MIB and Geosmin using granular activated carbon with and without MIEX pre-treatment. Water Res. 43 5151-5159. https://doi.org/10.1016/j. watres.2009.08.016

EE COMMISSION (2013) Directive 2013/39/EU of the European Parliament and of the Council of 12 August 2013 amending Directives 2000/60/EC and 2008/105/EC as regards priority substances in the field of water policy. Off. J. Eur. Union L226 1-17.

EE COMMISSION (2015) Commission implementing decision (EU) 2015/495 of 20 March 2015 establishing a watch list of substances for Union-wide monitoring in the field of water policy pursuant 
to Directive 2008/105/EC of the European Parliament and of the Council. Off. J. Eur. Union L78 40-42.

GROVER DP, ZHOU JL, FRICKERS PE and READMAN JW (2011) Improved removal of estrogenic and pharmaceutical compounds in sewage effluent by full scale granular activated carbon: Impact on receiving river water. J. Hazardous Mater. 185 1005-1011. https://doi. org/10.1016/j.jhazmat.2010.10.005

HNATUKOVA P, KOPECKA I and PIVOKONSKY M (2011) Adsorption of cellular peptides of Microcystis aeruginosa and two herbicides onto activated carbon: Effect of surface charge and interactions. Water Res. 45 3359-3368. https://doi.org/10.1016/j. watres.2011.03.051

IVAACEV-TUMBAS I and HOBBY R (2010) Removal of organic xenobiotics by combined out/in ultrafiltration and powdered activated carbon adsorption. Desalination 255 124-128. https://doi. org/10.1016/j.desal.2010.01.005

JOHNSON AC, AERNI HR, GERRITSEN A, GIBERT M, GIGER W, HGLLAND K, JÜRGENS M, NAKARI T, PICKERING A, SUTER MJF, SVENSON A and WETTSTEIN FE (2005) Comparing steroid estrogen, and nonylphenol content across a range of European sewage plants with different treatment and management practices. Water Res. 39 47-58. https://doi.org/10.1016/j.watres.2004.07.025

JOSEPH L, BOATENG LK, FLORA JRV, PARK YG, SON A, BADAWYD $M$ and YOON Y (2013) Removal of bisphenol A and 17a-ethinyl estradiol by combined coagulation and adsorption using carbon nanomaterials and powdered activated carbon. Sep. Purif. Technol. 107 37-47. https://doi.org/10.1016/j.seppur.2013.01.012

KARPOVA TS, KALLAS PREIS J, LUCIANA A and TORRES B (2007) Selective photocatalytic oxidation of steroid estrogens in presence of saccharose and ethanol as co-pollutants. Environ. Chem. Lett. 5 219-224. https://doi.org/10.1007/s10311-007-0103-4

KUCH HM and BALLSCHMITTER K (2001) Determination of endocrine-disrupting phenolic compounds and estrogens in surface and drinking water by HRGC-(NCI)-MS in the picogram per liter range. Environ. Sci. Technol. 35 3201-3206. https://doi.org/10.1021/ es010034m

LEE SH, LEE JW, KIM S, PARK PK, KIM JH and LEE CH (2009) Removal of $17 \beta$-estradiol by powdered activated carbonMicrofiltration hybrid process: The effect of PAC deposition on membrane surface. J. Membrane Sci. 326 84-91. https://doi. org/10.1016/j.memsci.2008.09.031

LOO SL, FANE AG, KRANTZ WB and LIM TT (2012) Emergency water supply: A review of potential technologies and selection criteria. Water Res. 46 3125-3151. https://doi.org/10.1016/j. watres.2012.03.030

MA C, QIN D, SUN Q, ZHANG F, LIU H and YU CP (2016) Removal of environmental estrogens by bacterial cell immobilization technique. Chemosphere 144 607-614. https://doi.org/10.1016/j. chemosphere.2015.09.014
MOZIA S and TOMASZEWSKA M (2004) Treatment of surface water using hybrid processes-adsorption on PAC and ultrafiltration. Desalination 162 23-31. https://doi.org/10.1016/ S0011-9164(04)00023-2

NIE M, YANG Y, LIU M, YAN C, SHI HAO, DONG W and ZHOU JL (2014) Environmental estrogens in a drinking water reservoir area in Shanghai:Occurrence, colloidal contribution and risk assessment. Sci. Total Environ. 487 785-79. https://doi.org/10.1016/j. scitotenv.2013.12.010

PÉREZ RL and ESCANDAR GM (2014) Liquid chromatography with diode array detection and multivariate curve resolution for the selective and sensitive quantification of estrogens in natural waters. Anal. Chim. Acta 835 19-28. https://doi.org/10.1016/j. aca.2014.05.015

RIVERA-UTRILLA J, MÉNDEZ-DÍAZ J, SÁNCHEZ-POLO M, FERRO-GARCÍA MA and BAUTISTA- TOLEDO I (2006) Removal of the surfactant sodium dodecylbenzenesulphonate from water by simultaneous use of ozone and powdered activated carbon: comparison with systems based on $\mathrm{O} 3$ and $\mathrm{O} 3 / \mathrm{H} 2 \mathrm{O} 2$. Water Res. 40 1717-1725. https://doi.org/10.1016/j.watres.2006.02.015

SCHENCK K, ROSENBLUM L, WIESE TE, WYMER L, DUGAN N, WILLIAMS D, MASH H, MERRIMAN B and SPETH T (2012) Removal of estrogens and estrogenicity through drinking water treatment. J. Water Health 10 (1) 43-55. https://doi.org/10.2166/ wh.2011.135

SONG KY, PARK PK, KIM JH, LEE CH and LEE S (2009) Coupling effect of $17 \beta$-estradiol and natural organic matter on the performance of a PAC adsorption/membrane filtration hybrid system. Desalination 237 392-399. https://doi.org/10.1016/j.desal.2008.11.004

URMENYI AM, POOT AA, WESSLING M and MULDER MHV (2005) Affinity membranes for hormone removal from aqueous solutions. J. Membrane Sci. 259 91-102. https://doi.org/10.1016/j. memsci.2005.03.008

YOON Y, WESTERHOFF P, SNYDER SA, WERT EC and YOON J (2007) Removal of endocrine disrupting compounds and pharmaceuticals by nanofiltration and ultrafiltration membranes. Desalination 202 16-23. https://doi.org/10.1016/j.desal.2005.12.033

YOON YM, WESTERHOFF P, SNYDER SA and ESPARZA M (2003) HPLC-fluorescence detection and adsorption of bisphenol A, 17beta-estradiol, and 17alphaethynyl estradiol on powdered activated carbon. Water Res. 37 3530-3537. https://doi.org/10.1016/ S0043-1354(03)00239-2

YURIY SP (2006) Hollow-fiber membrane adsorber: mathematical model. J. Membrane Sci. 280 610-623. https://doi.org/10.1016/j. memsci.2006.02.019 